\title{
FACTORS AFFECTING SIGN VISIBILITY, CONSPICUITY AND LEGIBILITY: REVIEW AND ANNOTATED BIBLIOGRAPHY
}

\author{
John D. Bullough, Ph.D. \\ Lighting Research Center, Rensselaer Polytechnic Institute \\ 21 Union Street, Troy, NY 12180 \\ Email: bulloj@rpi.edu, Web: www.lrc.rpi.edu
}

\begin{abstract}
This paper summarizes published research studies, technical reports and codes and standards related to the visibility (i.e., conspicuity and legibility) of signage. In the summary that follows, publications are grouped and discussed according to several different topics. First, the typographic and symbolic characteristics of signs and the information they carry are described (e.g., letter size, font selection, etc.); second, photometric, colorimetric and temporal properties of signs as they affect visibility; finally, environmental considerations (e.g., daytime versus nighttime viewing, whether a sign is located in a rural or urban area, etc.) as they influence sign design are reviewed. Annotated summaries of each publication in the literature review are included at the end of this paper.
\end{abstract}

\section{INTRODUCTION}

Signs form a critical part of the visual outdoor environment. They provide key wayfinding cues to drivers and pedestrians about the locations of businesses and other places of commercial and government activity, and they serve as landmarks for navigating through many urban, suburban and even rural areas. Of course, many signs also serve the purpose of advertising for, and increasing awareness about, the businesses that install and use them. Undoubtedly it is the intent of every sign installation to be both noticeable and legible. Noticeability, or conspicuity, is the property of standing out from one's environment or surroundings. Legibility is the property of being able to be read and understood clearly. Factors that make a sign noticeable are not always the same that make them legible under the same conditions. For example, temporal modulation such as flashing is often employed in applications of signal lights to make them more conspicuous (Crawford, 1962), but flashing often renders text more difficult to read (Milburn and Mertens, 1997). Similarly, increasing the luminance or brightness of a sign would generally be expected to increase its noticeability (Schieber and Goodspeed, 1997) but excessive brightness can lead to irradiation of the characters and symbols on the sign (Cornog and Rose, 1967), reducing their legibility.

A challenge to reviewing the characteristics of signs as they relate to aspects such as conspicuity or legibility is that these factors are, in turn, dependent upon the specific conditions that are present when a particular sign is being viewed by a particular individual. Different signs have different purposes: highway signs may provide regulatory information (e.g., stop, speed limit) or navigational cues (e.g., street signs). Others may serve as landmarks for commercial businesses, or simply reinforce a brand identity. Obviously, requirements for these purposes differ. Further, an individual observer's age, mood, and state of distraction can render a nominally adequate sign virtually invisible, whereas in many experimental studies, observers are sober, alert and generally compliant to experimenter instructions. Many of the studies reviewed in this paper used a specific context when investigating sign characteristics. The present review 
Factors Affecting Sign Visibility, Conspicuity and Legibility

Bullough, J. D.

Interdisciplinary Journal of Signage and Wayfinding; Volume 1; Issue 2

focuses on the visual acquisition of text as it might be viewed by a vehicle driver with reasonably good visual faculties and alertness. Application to individuals impaired by sensory limitations, distraction or other factors, is necessarily imperfect.

\section{TYPOGRAPHIC AND SYMBOLIC CHARACTERISTICS}

\subsection{Conspicuity}

Perhaps because signs, by their nature, are supposed to attract attention of drivers and pedestrians, conspicuity (the ability to detect the sign) is less studied than legibility (the ability to read and process the information on the sign). Nonetheless, a few typographic and symbolic factors have been demonstrated to affect conspicuity of signs.

One of the most obvious may be the size of the sign itself. The U.S. Small Business Association (U.S. SBA, 2003) provides guidelines for the size of signs based on the speed of approaching traffic; for example, larger signs are recommended for posted speeds of $55 \mathrm{mph}$ than for $25 \mathrm{mph}$. Bertucci (2003) describes a calculation method for determine the necessary size of an on-premise sign based not only on a vehicle's traveling speed but also on the type of reaction needed (e.g., whether a driver will need to make a driving maneuver based on the content of the sign).

Forbes (1972) devised a model for estimating the distance at which a highway sign, such as a guide sign, can be detected, and one of the factors incorporated into the model is the contrast between the letters on the sign and the rest of the sign itself. Higher contrast is predicted to ease detection of the sign at a greater distance, making it more conspicuous.

Finally, adding a border around the sign itself will often enhance the conspicuity of the sign. Possibly because the exact contrast between a sign and its background cannot always be known, when a sign is outlined by a border it may be easier to pick out as a (usually) rectangular object among other visual stimuli along the road, and FHWA (2004) requires this for almost all highway signs. Gates et al. (2004) found in real-world installations that a red reflectorized border around highway speed limit signs increased conformity with the sign's posted speed limit, suggesting that the border may have helped make the sign more difficult to ignore.

\subsection{Legibility}

Many more studies of the legibility of signs and factors that influence the reader's ability to process the information on the sign have been conducted. Reading and understanding a sign and being able to respond to it (by executing a turning maneuver, for example) takes time, during which the sign must be legible. That time is estimated by Kuhn et al. (1997) to be about 5.5 seconds; the Town of Bermuda Run (2013) uses a processing time of $8 \mathrm{~s}$ in its design guidelines for signs. Related to processing time, the amount of information that should be included on a sign has been addressed in research as well as municipal standards. While Hawkins and Rose (2005) found that there are few negative consequences of combining dual logos into a single logo space on blue service signs used along highway exits, graphical information such as logos will certainly differ from textual information on a sign, and accordingly there are cautions against packing too much information on a sign (City of Davis, 2010). The City of Saratoga Springs (2012) suggests a maximum of 8 words per sign. 
Factors Affecting Sign Visibility, Conspicuity and Legibility

Bullough, J. D.

Interdisciplinary Journal of Signage and Wayfinding; Volume 1; Issue 2

The amount of information on a sign can also be related to the size of the sign itself. Several municipal codes limit the percentage of a sign's area that can be covered by letters or symbols on the basis that an overly crowded sign will be less legible. The maximum amount of a sign's area that it permitted to contain characters ranges from 40\% (Town of Huntersville, 2009) up to 75\% (City of West Hollywood, 2002; City of Davis, 2010; City of Bellflower, 2016).

Related to the study by Hawkins and Rose (2005), evidence suggests that legibility can also be improved by using graphical symbols rather than alphanumeric characters, at least for highway signs (Kuhn et al., 1997). This is also reflected in municipal code language presumably addressing on-premise signs (City of West Hollywood, 2002). It may be worth noting, however, that the use of symbols can lead to longer and more frequent visual fixations by drivers, which is not always a desirable response (Pankok et al., 2015). Additionally, text has a natural visual scan pattern (e.g., left to right, from top to bottom) whereas the presence of symbols on highway signs may result in less consistent and less efficient visual scanning (Pankok et al., 2015). When symbols are used, some literature on display effectiveness suggests that they should be simple (Duncanson, 1994), since not all symbols are equally legible when displayed on a highway sign (Schnell et al., 2004). Nonetheless, in addition to aiding in legibility, symbols can reinforce desired behaviors in drivers (e.g., yielding to pedestrians in crosswalks) when they accompany other types of visual information such as warning beacons (Van Houten et al., 1998), and are powerful elements of communication.

For signs using alphanumeric characters, the impacts of typeface or font on legibility have been investigated by many researchers. Appropriate font use can result in smaller footprints of the text on a sign while simultaneously improving legibility, as found in a study of roadside signs used near national parks (Garvey et al., 2004). On highway signs, an alternative font, Clearview, was found in several experimental studies (Garvey et al., 1997, 2016; Hawkins et al., 1999) to result in greater legibility distances. Studies using other fonts led to several empirical conclusions: Bank Gothic Light, Dutch Regular and Dutch Bold fonts were found to result in superior acuity than Commercial Script Regular (Garvey et al., 2001); the latter is a script font similar to cursive handwriting. The Futura font was found to be as legible as standard highway fonts for wayfinding signs in another study (Garvey, 2007). Municipalities tend to discourage the use of script-type fonts that emulate handwriting for on-premise signs because of their reduced legibility (Town of Bermuda Run, 2013; City of Bellflower, 2016), although municipal code language tends to be qualitative and not specific regarding specific type fonts that may or may not be used.

One of the distinguishing features among different fonts is the presence or not of serifs, and a few studies have evaluated the extent to which serifs impact legibility. The bulk of the evidence (Carter et al., 1985; Kuhn et al., 1998) suggests that there are no legibility differences between serif and non-serif fonts. In contrast, Tinker (1966) summarizes research stating that serifs aid in legibility. Arditi and Cho (2005) found no differences at suprathreshold visibility levels, but near the acuity limit, found fonts with serifs to be beneficial. Only one example in which non-serif fonts outperformed serif fonts was identified (Yager et al., 1998), but this effect only occurred at low light levels; at higher light levels, serifs made no difference on legibility. With the exception of the study by Kuhn et al. (1998), most of these studies have investigated legibility for paper- or screen-based reading tasks rather than for larger-format signs. 
Factors Affecting Sign Visibility, Conspicuity and Legibility

Bullough, J. D.

Interdisciplinary Journal of Signage and Wayfinding; Volume 1; Issue 2

Fonts can also differ in their geometric characteristics (e.g., aspect ratio, stroke width, etc.). The width of the individual characters seems to have a large impact on legibility, larger than stroke width or the spacing between characters for both printed text and signs (Young et al., 1992; Garvey et al., 2001). Further, character width seems to influence the relationships between factors like the spacing between characters and legibility; reducing space between characters may be beneficial for wider characters, but detrimental for narrow ones in printed text (Young et al., 1992). Some guidelines suggest that when a sign character's width and height are the same, its legibility is maximized (CIDEA, 2010). While it may be a less important factor than character width, stroke width has received much interest in the research literature leading to guidelines for optimal stroke width (Forbes et al., 1965; Tinker, 1966; Kuhn et al., 1997; Holick and Carlson, 2002). One recommendation is that stroke width be $18 \%$ of the character height (Tinker, 1966), but even this factor interacts with others like the contrast polarity of the text (Kuhn et al., 1997). A font factor that impacts legibility for "dotted" fonts like those used in exposed-lamp or matrix signs is the spacing between lamps or matrix elements; Rea (2000) provides guidelines on spacing between elements for ensuring legibility.

Obviously, the size of text influences legibility (Rea and Ouellette, 1991).

Unsurprisingly, many studies using visual display and sign contexts (Duncanson, 1994; Bernard et al., 2001; Ullman et al., 2005; Bullough and Skinner, 2016) suggest that larger letter sizes result in improved legibility, but the range of conditions used in those studies are important for generalization of these findings, since some authors report that there is a range of letter sizes above which legibility of printed text can degrade (Carter et al., 1985). A wealth of guidelines derived from research with on-premise signs (Bertucci, 2006; CIDEA, 2010; Bertucci and Crawford, 2015) and employed in municipal and other standards on font size exist, most specifying minimum letter size (City of West Hollywood, 2002; U.S. SBA, 2003; FHWA, 2004; ISA, 2007; Town of Huntersville, 2009; Millar, 2011), but sometimes recommending a range of appropriate sizes (Carter et al., 1985; Town of Bermuda Run, 2013). Most of the time, the letter height is used to quantify the letter size, but as found by Rea and Ouellette (1991) and Cai and Green (2009), the projected area of the character is a more complete specification of the size of the stimulus for letters and symbols on signs.

Other properties of sign characters aside from font and size influence legibility. The contrast of letters against the sign itself is one of the most critical (Rea and Ouellette, 1991; Schnell et al., 2004). Similar to research on letter size, higher contrast of display symbols and characters is generally thought to improve legibility (Shurtleff et al., 1966) and this is included in municipal sign standards (City of West Hollywood, 2002; Town of Huntersville, 2009; City of Davis, 2010) but some sources report an optimal contrast value, perhaps to avoid excessive brightness of characters or of the sign (see "Photometric, Colorimetric and Temporal Characteristics"). For example, Kuhn et al. (1997) report that the contrast between an on-premise sign and its characters best supports legibility when the luminance ratio between the brighter and the less bright of the two is 12:1. Importantly, it should be recalled that luminance contrast differs from color contrast; green letters on a red sign might have no luminance contrast but could still be visible because of the difference in colors. However, luminance contrast of printed text or of highway sign characters is substantially more important to legibility than color contrast (Forbes et al., 1965; Tinker, 1966), which only significantly affects legibility when the luminance contrast is low (Eastman, 1968), a situation that should be avoided in signs. 
Factors Affecting Sign Visibility, Conspicuity and Legibility

Bullough, J. D.

Interdisciplinary Journal of Signage and Wayfinding; Volume 1; Issue 2

The polarity of contrast can also impact the degree of legibility a sign or other printed text exhibits. A majority of the research evidence reviewed (Tinker, 1966; Kuhn et al., 1997, 1998; CIDEA, 2010) is consistent of the notion that positive contrast (letters with higher luminances than the sign face) offers better legibility than negative contrast text. Because of this municipal guidance seems to favor positive contrast text (Town of Bermuda Run, 2013). Nonetheless, there are several reports that report no difference in legibility between positive and negative contrast text (Shurtleff et al., 1966; Lerner and Collins, 1983).

Contrast can also be a factor within individual characters on a sign, particularly for illuminated signs. Freyssinier et al. (2003) conducted evaluations of internally-illuminated sign letters and found that they began to be judged as unacceptable when the luminance contrast within different portions of the letters exceeded 0.2-0.4. Intentional contrast variations within letters occur when letters and other characters are rendered in an outline form rather than as a solid character. All of the research that has investigated the relative impact of outline versus solid letters has found outline characters to provide less legibility than solid ones (Lerner and Collins, 1983; Duncanson, 1994; Arditi et al., 1997), whether for printed text, visual displays or signs.

Finally, many investigations have been conducted regarding the use of all-uppercase versus mixed-case text on signs. In principal, because uppercase letters are larger than lowercase, the legibility of individual uppercase letters ought to be better than that of lowercase letters, and one investigation using single short, isolated words on an otherwise empty display screen did find slight advantages to displaying those words in all-uppercase text (Kinney and Showman, 1967). Nonetheless, most researchers who have investigated this question concluded that mixedcase text on displays and on signs improves legibility (Carter et al., 1985; Kuhn et al., 1997; Bertucci and Crawford, 2015), because it better differentiates among word-forms that would otherwise be similar using all-uppercase text. Accordingly, municipal guidance (Town of Bermuda Run, 2013) recommends mixed-case text for on-premise signs.

\section{PHOTOMETRIC, COLORIMETRIC AND TEMPORAL CHARACTERISTICS}

\subsection{Conspicuity}

Among the photometric properties of signs most related to conspicuity is the sign luminance (Elstad et al., 1962; Allen et al., 1967; Rea, 2000; AASHTO, 2005). In addition to ensuring that a sign is conspicuous, there are also concerns about ensuring that the luminance of a sign does not lead to distraction (ILE, 2001; Bullough and Skinner, 2011), especially among municipalities (City of Hutto, 2014; City of Mesa, undated). Table 1 summarizes research findings and recommendations from sign codes and standards regarding the range of luminances recommended for sign conspicuity while aiming to prevent distraction from overly bright signs, whether they are highway signs or commercial (on- or off-premise) signs.

Forbes (1972) developed a calculation method for estimating the detection distance of a highway sign, which uses the luminance of the sign (in contrast with the luminance of the ambient environment) as one of the factors crucial for detection. Not surprisingly, higher sign luminances tend to make highway signs easier to detect at night (Forbes et al., 1967) but not always in the daytime, where both dark signs and bright signs may be advantageous for conspicuity over intermediate sign brightness (Forbes et al., 1967), presumably because it is the contrast between a sign and its ambient environment that assists in detection (Kuhn et al., 1997). 
Factors Affecting Sign Visibility, Conspicuity and Legibility

Bullough, J. D.

Interdisciplinary Journal of Signage and Wayfinding; Volume 1; Issue 2

The impact of sign luminance on conspicuity interacts with factors such as the visual complexity of the ambient environment (Schieber and Goodspeed, 1997) where improvements with higher luminance are only seen in the more complex visual environments, and this would explain why illumination levels recommended for signs are higher in brighter ambient environments (Rea, 2000). Increases in sign luminance have not always been accompanied by a higher proportion of appropriate driving maneuvers in response to roadway signs (Powers, 1965). It should also be noted that the color of a sign may impact its conspicuity; Gates et al. (2004) found advantages of fluorescent colors on highway signs in terms of the driving maneuvers that were exhibited when they were present, potentially indicating that those colors assisted in detecting the signs.

An approach for limiting the apparent brightness of a digital billboard sign was proposed by Lewin (2008). The illuminance from the sign at a particular distance from the sign along the road should not exceed $3 \mathrm{~lx}$. This approach can allow the user to approximate the average luminance of a sign whose dimensions are known, but it cannot identify whether the luminance of the brightest portion of the sign might be judged excessive by observers. This is important because in a study of large-area light sources, ratings of the discomfort glare depend not only on the illuminance from the source but the maximum luminance of that source. Two light sources with the same average luminance can differ substantially in the amount of discomfort glare they produce (Bullough and Sweater Hickcox, 2012). If this finding can be extended to signs, quantifying the illuminance alone from a sign might not be sufficient to avoid problems.

An additional factor that can influence a sign's conspicuity is the presence of flashing, moving or animated content on the sign. Temporal changes in luminance or color will make a display or sign more conspicuous (Crawford, 1962; Forbes et al., 1965) and will attract more glances from drivers than static sign content on advertising signs (Beijer et al., 2004). Despite little hard evidence that dynamic advertising sign content reduces driving safety in terms of crashes (Smiley et al., 2005), many municipal codes prohibit flashing or moving sign content (City of Melbourne, 2009; City of Davis, 2010; City of Hutto, 2014; City of Mesa, undated) to avoid distraction from overly conspicuous commercial signage. 
Factors Affecting Sign Visibility, Conspicuity and Legibility

Bullough, J. D.

Interdisciplinary Journal of Signage and Wayfinding; Volume 1; Issue 2

\begin{tabular}{|c|c|c|c|}
\hline Source & $\begin{array}{c}\text { Minimum } \\
\text { Luminance } \\
\left(\mathbf{c d} / \mathbf{m}^{2}\right)\end{array}$ & $\begin{array}{c}\text { Maximum } \\
\text { Luminance } \\
\left(\mathrm{cd} / \mathrm{m}^{2}\right)\end{array}$ & Relevant Conditions \\
\hline \multirow{3}{*}{$\begin{array}{l}\text { Allen et al. } \\
\text { (1962) }\end{array}$} & 35 & 100 & Night, rural \\
\hline & 70 & 340 & Night, illuminated highway \\
\hline & 700 & 1700 & Night, very bright urban \\
\hline \multirow{3}{*}{$\begin{array}{l}\text { AASHTO } \\
(2005)\end{array}$} & 20 & 40 & Night, low ambient brightness \\
\hline & 45 & 90 & Night, medium ambient brightness \\
\hline & 90 & 180 & Night, high ambient brightness \\
\hline \multirow{2}{*}{$\begin{array}{l}\text { Bullough and } \\
\text { Skinner (2011) }\end{array}$} & & 280 & Night \\
\hline & & 23,000 & Day \\
\hline \multirow{2}{*}{$\begin{array}{l}\text { City of Hutto } \\
\text { (2014) }\end{array}$} & & 500 & Night \\
\hline & & 7000 & Day \\
\hline \multirow{2}{*}{$\begin{array}{l}\text { City of Mesa } \\
\text { (undated) }\end{array}$} & & $\begin{array}{c}1125 \text { red } \\
2250 \text { green } \\
1675 \text { amber } \\
2500 \text { full } \\
\text { color }\end{array}$ & Night \\
\hline & & $\begin{array}{c}3150 \text { red } \\
6300 \text { green } \\
4690 \text { amber } \\
7000 \text { full } \\
\text { color }\end{array}$ & Day \\
\hline \multirow[t]{2}{*}{$\begin{array}{l}\text { Elstad et al. } \\
(1962)\end{array}$} & 35 & 70 & Night, rural or suburban \\
\hline & 250 & 400 & Night, bright urban \\
\hline \multirow{6}{*}{ ILE (2001) } & & 300 & Night, large sign, low ambient brightness \\
\hline & & 600 & $\begin{array}{l}\begin{array}{l}\text { Night, large sign, medium/high ambient } \\
\text { brightness }\end{array} \\
\end{array}$ \\
\hline & & 100 & Night, small sign, intrinsically dark area \\
\hline & & 600 & Night, small sign, low ambient brightness \\
\hline & & 800 & Night, small sign, medium ambient brightness \\
\hline & & 1000 & Night, small sign, high ambient brightness \\
\hline \multirow{5}{*}{ Rea (2000) } & 70 & 350 & Night, lighted fascia \\
\hline & 250 & 500 & Night, bright fascia \\
\hline & 450 & 700 & Night, low ambient brightness \\
\hline & 1000 & 1400 & Night, average commercial area \\
\hline & 1400 & 1700 & Night, emergency traffic control \\
\hline
\end{tabular}

Table 1. Sign luminance recommendations for conspicuity and minimizing distraction.

\subsection{Legibility}

Sign luminance can have important effects on legibility. Recommendations for highway and commercial sign luminances to ensure legibility are shown in Table 2 . Luminances need to be 
Factors Affecting Sign Visibility, Conspicuity and Legibility

Bullough, J. D.

Interdisciplinary Journal of Signage and Wayfinding; Volume 1; Issue 2

high enough to ensure adequate readability, but if luminances are too high, legibility can be reduced (Garvey et al., 2009) by factors such as irradiation (Cornog and Rose, 1967). Increasing luminance can sometimes help counteract reduced visibility caused by factors such as small letter size (Tinker, 1966), but if legibility is already high, increasing luminance may have little effect on further legibility improvements (Bullough and Skinner, 2016). Several studies have investigated the interactions between luminance and other factors such as typographic and observer characteristics (Yager et al., 1998; Holick and Carlson, 2002; Schnell et al., 2004, 2009) for highway signs and visual displays. The uniformity of sign luminance can also influence legibility, and recommendations for uniformity as well as its absolute value can be found for highway signs (AASHTO, 2005).

\begin{tabular}{|c|c|c|c|}
\hline Source & $\begin{array}{c}\text { Minimum } \\
\text { Luminance } \\
\left(\mathbf{c d} / \mathbf{m}^{2}\right)\end{array}$ & $\begin{array}{c}\text { Optimal } \\
\text { Luminance } \\
\left(\mathbf{c d} / \mathbf{m}^{2}\right)\end{array}$ & Relevant Conditions \\
\hline Allen (1958) & & 35 & Night, rural \\
\hline $\begin{array}{l}\text { Charness et al. } \\
\text { (1999) }\end{array}$ & & 100 & For reading \\
\hline \multirow{3}{*}{$\begin{array}{l}\text { Fletcher et al. } \\
(2009)\end{array}$} & & 20 & $\begin{array}{l}\text { Dark conditions, character luminance, positive } \\
\text { contrast }\end{array}$ \\
\hline & & 60 & $\begin{array}{l}\text { Bright conditions, character luminance, positive } \\
\text { contrast }\end{array}$ \\
\hline & & 1 & Positive contrast \\
\hline \multirow{2}{*}{$\begin{array}{l}\text { Freyssinier et al. } \\
(2006)\end{array}$} & & $40-190$ & No adjacent signs present \\
\hline & & $65-230$ & Adjacent signs present \\
\hline \multirow{4}{*}{$\begin{array}{l}\text { Graham et al. } \\
\text { (1997) }\end{array}$} & & 30 & Night, younger observer from $90 \mathrm{~m}$ \\
\hline & & 2 & Night, younger observer from $60 \mathrm{~m}$ \\
\hline & & 40 & Night, older observer from $90 \mathrm{~m}$ \\
\hline & & 7 & Night, older observer from $60 \mathrm{~m}$ \\
\hline $\begin{array}{l}\text { Kuhn et al. } \\
\text { (1997) }\end{array}$ & 2.4 & 75 & Night \\
\hline $\begin{array}{l}\text { Shurtleff et al. } \\
\text { (1966) }\end{array}$ & & $70-140$ & For reading \\
\hline
\end{tabular}

Table 2. Minimum and optimal sign luminance recommendations for legibility.

In addition to luminance, the impacts of sign color(s) on legibility have also been addressed, albeit in a more limited manner than luminance. Funkhouser et al. (1999) compared green and purple traffic signs during daytime and nighttime driving tests and found drivers responded to them equivalently. Flashing or animated content, while increasing conspicuity (see above) will also tend to make text on visual displays more difficult to read (Milburn and Mertens, 1997), and this is probably also the case for outdoor signs.

The type of lighting used on illuminated signage will strongly influence the ease with which the sign can be read. Kuhn et al. (1998) and Garvey and Kuhn (2011) report that internally-illuminated and neon commercial signs provide superior legibility to externallyilluminated signs. This is also reflected in municipal standards that indicate a preference for 
Factors Affecting Sign Visibility, Conspicuity and Legibility

Bullough, J. D.

Interdisciplinary Journal of Signage and Wayfinding; Volume 1; Issue 2

internal or back-lighting over external illumination (City of Bellflower, 2016) for signs. However, some municipalities also discourage the use of neon signage (City of West Hollywood, 2002; City of Davis, 2010). The potential influence of taste or aesthetics in municipal sign codes is not fully understood and could underlie some of these recommendations.

Possible reasons for reduced legibility with external illumination systems include the potential for glare, which is why many standards require external light sources used to illuminate commercial and highway signs to be shielded from view (City of West Hollywood, 2002; AASHTO, 2005; City of Davis, 2010). External lighting might also serve as a distraction from the message content on a sign, so it should be designed to be as inconspicuous as possible (City of Saratoga Springs, 2012). Because of such difficulties with external lighting, as well as challenges with maintenance and costs like energy use, highway signs often use retroreflective sign sheeting materials in lieu of lighting to support nighttime legibility (Bullough et al., 2010). Retroreflectivity does not seem to be commonly used in on-premise or advertising signs.

\section{ENVIRONMENTAL CHARACTERISTICS}

\subsection{Conspicuity}

Not all factors that alter the visibility of signs are under the direct control of sign designers. In addition to the characteristics of the observer described previously in this paper, the environment in which a sign is located can strongly affect its visibility. In terms of sign conspicuity, one factor that will impact the conspicuity of a sign is the ambient brightness level, which can lead to different recommendations for sign or display luminance (Elstad et al., 1962; Rea, 2000; ILE, 2001; AASHTO, 2005; Fletcher et al., 2009) or the illuminance on signs (Rea, 2000), as illustrated by many of the findings listed in Table 1 . Indeed, the contrast between a highway or an on-premise sign and its ambient background is an important predictor of how far away the sign can be detected (Forbes, 1972; Kuhn et al., 1997), such that the darkest and brightest signs may be most conspicuous against daytime background conditions (Forbes et al., 1967) but signs similar in luminance to the background will be less conspicuous.

The degree of visual complexity where a sign is located will also impact how easily it can be detected. For example, under visually simple conditions, traffic sign detection distances were reported by Akagi et al. (1996) to be nearly twice their value under visually complex conditions.

\subsection{Legibility}

The ambient environmental conditions play an important role in the legibility of signs. One of the more obvious factors may be daytime versus nighttime. Even though many signs at night are equipped with some type of illumination (e.g., internal, back-lighting or external), legibility distances under daytime conditions will tend to be substantially longer than under nighttime conditions (Zwahlen and Schnell, 1998; Ullman et al., 2005; Garvey et al., 2009) whether they are highway signs or on-premise signs.

The visual complexity of the ambient environment not only impacts a sign's conspicuity, but also its legibility. Bertucci and Crawford (2015) stated that it is necessary to reduce the legibility index (the distance at which a sign of a given size can be read) under medium-to-highcomplexity visual environments, relative to low-complexity environments. Freyssinier et al. (2006) found that the luminances needed to achieve high levels of sign readability increased 
Factors Affecting Sign Visibility, Conspicuity and Legibility

Bullough, J. D.

Interdisciplinary Journal of Signage and Wayfinding; Volume 1; Issue 2

when an internally-illuminated sign was adjacent to other nearby signs, compared to when the same sign was visually isolated from other signs.

The viewing geometry and location of a sign will also influence the degree to which it can be easily read. An important factor related to signage is the viewing angle. Highway signs, for instance, are generally mounted such that the sign face is perpendicular to the lines of sight for oncoming traffic, while some building-mounted signs are mounted with the sign face nearly parallel to the line of sight. This reduces the projected solid angle of letters in the direction of a driver trying to read a sign or display (Cai and Green, 2009) even if the letter height is unchanged, and will accordingly reduce its legibility. Garvey (2006) reports that the legibility of commercial signs begins to be compromised when the viewing angle exceeds $20^{\circ}-40^{\circ}$ from the perpendicular to the line of sight.

Finally, the specific location of the sign can also make it more or less legible, perhaps because of driver expectations about where signs are likely to be located. Since many signs are located along the right-hand side of the road (in locations with right-side traffic patterns), drivers may be less attentive to signs on the left-hand side of the road, and it has been estimated (U.S. SBA, 2003) that commercial signs mounted on the left side of the road require letters to be larger to achieve equivalent legibility as signs on the right side.

\section{SUMMARY}

This review has identified several sources of technical research, industry rules of thumb and best practices, and consensus-based standards and codes, which describe how sign properties can affect visibility in terms of conspicuity and legibility, at least for the context of acquiring mainly textual information from commercial and traffic signs. Not included in this review are legal cases in which the results of research studies or requirements from municipalities have been tested by a court. Such a review could clarify the extent to which the findings summarized here can be generalized to different types of signs and signage applications.

From this review, it seems feasible that visual performance modeling can be used to predict the visibility of signs. However, current models may be incomplete regarding the influence of factors beyond luminance, size and contrast of signs and sign characters. Certainly, as described above, the characteristics of the observer (e.g., age, impairment, distraction) can confound any model predictions of a sign's conspicuity or legibility.

But even for model observers with good vision and who are attentive to signs, models of conspicuity or legibility can still have shortcomings. For example, highway sign characters subtending similar solid angles, and with similar photometric characteristics, will not yield similar legibility distances (Garvey et al., 2016). A fruitful area of exploration may be in developing quantitative adjustment factors relating the aspect ratio of sign characters to visual performance when size, luminance and contrast are held constant. Another factor that has not been considered in much of the reports reviewed here is the role of a sign's maximum luminance or luminance distribution on the noticeability of the sign or its potential to create distraction or glare. Subsequent investigation could explore this factor in an experimental setting. 
Factors Affecting Sign Visibility, Conspicuity and Legibility

Bullough, J. D.

Interdisciplinary Journal of Signage and Wayfinding; Volume 1; Issue 2

\section{ACKNOWLEDGMENTS}

Preparation of this manuscript was supported by the Signage Research Foundation under the project "Illuminated Sign Conspicuity: What Factors Make a Sign Noticeable and Legible," managed by Sapna Budev. Helpful input to this paper was provided by Jean Paul Freyssinier, Chris Gaudette, David Hickey, Kenneth Peskin, Deacon Wardlow and John Yarger.

\section{REFERENCES AND ANNOTATIONS}

Akagi Y, Seo T, Motoda Y. 1996. Influence of visual environments on visibility of traffic signs. Transportation Research Record 1553: 53-58.

- The average detection distances for signs decreased from $110 \mathrm{ft}$ with minimum visual noise to $60 \mathrm{ft}$ with high levels of visual noise.

Allen TM. 1958. Night legibility distances of highway signs. Highway Research Bulletin 191: 3-40.

- Optimal sign luminances for nighttime legibility were found to be around $35 \mathrm{~cd} / \mathrm{m}^{2}$.

Allen TW, Dyer FN, Smith GM, Janson MH. 1967. Luminance requirements for illuminated signs. Highway Research Record 167: 16-37.

- Minimum nighttime sign luminances of $35 \mathrm{~cd} / \mathrm{m}^{2}$ are appropriate in rural locations, with a maximum of $100 \mathrm{~cd} / \mathrm{m}^{2}$.

- On illuminated highways or in the presence of substantial glare from opposing vehicle headlights, sign luminances between 70 and $340 \mathrm{~cd} / \mathrm{m}^{2}$ are recommended.

- In very brightly lighted urban locations, a minimum luminance of $700 \mathrm{~cd} / \mathrm{m}^{2}$ with a maximum of $1700 \mathrm{~cd} / \mathrm{m}^{2}$ might be appropriate.

American Association of State Highway and Transportation Officials. 2005. Roadway Lighting Design Guide. Washington, DC: American Association of State Highway and Transportation Officials.

- Nighttime sign luminances in areas of low, medium and high ambient luminance should be $20-40 \mathrm{~cd} / \mathrm{m}^{2}, 45-90 \mathrm{~cd} / \mathrm{m}^{2}$ and $90-180 \mathrm{~cd} / \mathrm{m}^{2}$, respectively.

- A maximum-to-minimum sign luminance ratio of 6:1 is recommended.

- External lighting, if used, should not direct light into drivers' eyes.

Arditi A, Cho J. 2005. Serifs and font legibility. Vision Research 45: 2926-2933.

- Reading speed for normal-sighted and low vision observers did not differ whether fonts has serifs or not.

- Acuity was slightly improved when a font with serifs was used in place of one without serifs. 
Factors Affecting Sign Visibility, Conspicuity and Legibility

Bullough, J. D.

Interdisciplinary Journal of Signage and Wayfinding; Volume 1; Issue 2

Arditi A, Liu L, Lynn W. 1997. Legibility of outline and solid fonts with wide and narrow spacing. Trends in Optics and Photonics, 5 p.

- Acuity for outline fonts was worse for outline fonts than for solid fonts.

- Outline characters needed to be 1.8 times larger than solid characters for equivalent legibility.

Beijer D, Smiley A, Eizenman M. 2004. Observed driver glance behavior at roadside advertising signs. Transportation Research Record 1899: 96-103.

- Signs with dynamic content made up half of the signs observed in one study, but received $70 \%$ of glances by drivers.

- Active signs received twice as many glances as non-active ones.

Bernard M, Liao CH, Mills M. 2001. The effects of font type and size on the legibility and reading time of online text by older adults. Proceedings of the Conference on Human Factors in Computing Systems, pp. 175-176.

- On average, legibility by older people of 14-point type was greater than for 12-point type.

- A 12-point serif font was less legible than a 12-point non-serif font, but the reverse effect of serifs occurred at 14 points.

Bertucci A. 2003. On-Premise Signs: Guideline Standards. Bristol, PA: United States Sign Council Foundation.

- A methodology for calculating the necessary size of a sign for various conditions (e.g., vehicle speed, type of reaction needed, letter type) is presented.

Bertucci A. 2006. Sign Legibility: Rules of Thumb. Bristol, PA: United States Sign Council Foundation.

- A legibility index of $30 \mathrm{ft} /$ in is recommended for signage.

Bertucci A, Crawford R. 2015. Best Practice Standards for On-Premise Signs. Bristol, PA: United States Sign Council Foundation.

- Letter height needs to increase by $15 \%$ when all-uppercase letters are used, compared to mixed case.

- A legibility index of $30 \mathrm{ft} / \mathrm{in}$. is recommended for adequate sign legibility.

- In conditions of moderate visual complexity, the recommended legibility index should be multiplied by 0.83 ; under high complexity, the legibility index should be multiplied by 0.67 .

Bullough JD, Skinner NP. 2011. Luminance criteria and measurement considerations for light-emitting billboards. Transportation Research Board Annual Meeting, 7 p.

- A maximum allowable daytime billboard luminance of $23,000 \mathrm{~cd} / \mathrm{m}^{2}$ is proposed.

- A maximum allowable nighttime billboard luminance of $280 \mathrm{~cd} / \mathrm{m}^{2}$ is proposed. 
Factors Affecting Sign Visibility, Conspicuity and Legibility

Bullough, J. D.

Interdisciplinary Journal of Signage and Wayfinding; Volume 1; Issue 2

Bullough JD, Skinner NP. 2016 [in press]. High visibility reflective sign sheeting materials: Field and computational evaluations of visual performance. Transport, 9 p.

- The relative visual performance model shows that large changes in luminance have small impacts on visibility for highway signs.

- Font size is a primary reason signs are not legible from large distances.

Bullough JD, Skinner NP, O'Rourke CP. 2010. Legibility of urban highway traffic signs using new retroreflective materials. Transport 25: 229-236.

- Retroreflective materials can compensate for a lack of external sign illumination in overhead guide signs.

Bullough JD, Sweater Hickcox K. 2012. Interactions among light source luminance, illuminance and size on discomfort glare. Society of Automotive Engineers International Journal of Passenger Cars - Mechanical Systems 5(1): 199-202.

- Ratings of discomfort glare from large-area sources are influenced by the illuminance produced by the source at observers' eyes and by the maximum luminance of the source of glare.

Cai H, Green PA. 2009. Legibility index for examining common viewing situations: $A$ new definition using solid angle. Leukos 5(4): 279-295.

- A legibility index based on the subtended solid angle of a sign character rather than its height is proposed,

- The revised legibility index performed well at predicting critical legibility levels for many different viewing angles in which the characters' subtended angle would differ.

Carter R, Day B, Meggs P. 1985. Typographic Design: Form and Communication. New York, NY: Van Nostrand Reinhold.

- Text in all-uppercase letters is more difficult to read than mixed-case text.

- Serif and non-serif fonts can provide equal legibility.

- Research is described that finds the optimal font size at normal reading distances to be 912 points.

Center for Inclusive Design and Environmental Access. 2010. Design Resources: Text Legibility and Readability of Large Format Signs in Buildings and Sites, DR-11. Buffalo, NY: University at Buffalo.

- Research is cited stating that setting letter width to be the same as letter height results in greater legibility distances.

- A legibility index of $35 \mathrm{ft} /$ in. is recommended.

- Positive contrast text is recommended. 
Factors Affecting Sign Visibility, Conspicuity and Legibility

Bullough, J. D.

Interdisciplinary Journal of Signage and Wayfinding; Volume 1; Issue 2

Charness N, Dijkstra K., 1999. Age, luminance, and print legibility in homes, offices, and public places. Human Factors 41(2): 173-193.

- Reading task background luminances of $100 \mathrm{~cd} / \mathrm{m}^{2}$ are recommended for proficient reading.

City of Bellflower. 2016. Signage Design Guidelines. Bellflower, CA: City of Bellflower.

- Intricate typefaces for signs are prohibited.

- Lettering on a sign should not occupy more than $75 \%$ of the sign face area.

- The number of colors used on a sign should not exceed three.

- Excessively bright and fluorescent colors should be avoided.

- Internally-illuminated or back-lighted signs are preferred over external illumination.

City of Davis. 2010. Davis Citywide Sign Design Guidelines. Davis, CA: City of Davis.

- Messages on signs should be brief.

- Letters should occupy no more than $75 \%$ of the sign face area.

- High contrast between letters/symbols and their backgrounds should be used.

- External lighting should be shielded from view.

- Neon light signs are discouraged.

- Animation, blinking or other changes in intensity and color are prohibited.

City of Hutto. 2014. Site Design Standards. Hutto, TX: City of Hutto.

- Blinking or flashing on signs is prohibited.

- Electronic signs should not exceed a luminance of $7000 \mathrm{~cd} / \mathrm{m}^{2}$ during the daytime and $500 \mathrm{~cd} / \mathrm{m}^{2}$ during the nighttime.

City of Melbourne. 2009. An Ordinance of the City of Melbourne, Brevard County, Florida, Relating to Signs and Advertising. Melbourne, FL: City of Melbourne.

- Rotating or animated signs (except for changeable copy) are prohibited.

City of Mesa. [Undated.] Sign Regulations. Mesa, AZ: City of Mesa.

- Signs with flashing illumination or other animation or movement are prohibited.

- A sign with an LED display cannot exceed a luminance of 3150, 6300, 4690 or 7000 $\mathrm{cd} / \mathrm{m}^{2}$ for red, green, amber or full color signs, respectively, during daytime; or 1125, 2250,1675 or $2500 \mathrm{~cd} / \mathrm{m}^{2}$ for red, green, amber or full color signs, respectively, during nighttime.

- Light sources for any external illumination should not be directly visible.

City of Saratoga Springs. 2012. Signage: Historic District Design Guidelines. Saratoga Springs, NY: City of Saratoga Springs.

- Sign messages should be short (no more than 8 words) and use three or fewer colors.

- Light sources for external illumination should be inconspicuous. 
Factors Affecting Sign Visibility, Conspicuity and Legibility

Bullough, J. D.

Interdisciplinary Journal of Signage and Wayfinding; Volume 1; Issue 2

City of West Hollywood. 2002. Sign Design Guidelines. West Hollywood, CA: City of West Hollywood.

- Contrasting colors between letters and the sign background should be used to maximize legibility.

- An excessive number of sign colors can reduce legibility.

- A sign designed to be viewed from $60 \mathrm{ft}$ requires $3.5 \mathrm{in}$. letters; to be viewed from $100 \mathrm{ft}$ requires 5.5-6 in. letters.

- Symbols and pictograms are stated to be more effective than text.

- Letters should not take up more than $75 \%$ of the space on a sign panel.

- External sign lighting should be shielded to avoid glare; back lighting is encouraged.

Cornog DY, Rose FC. 1967. Legibility of Alphanumeric Characters and Other Symbols, II: A Reference Handbook. Washington, DC: National Bureau of Standards.

- Excessive brightness of a display can lead to irradiation that reduces legibility of characters and symbols.

Crawford A. 1962. The perception of light signals: The effect of the number of irrelevant lights. Ergonomics 5: 417-428.

- Flashing lights increase their conspicuity relative to steady lights.

Duncanson JP. 1994. Visual and Auditory Symbols: A Literature Review. Atlantic City, NJ: Federal Aviation Administration.

- It is proposed that an effective sign symbol is simple rather than complex, large rather than small, and solid rather than hollow or outlined.

Eastman AA. 1968. Color contrast versus luminance contrast. Illuminating Engineering 63: 67.

- Color contrast has little to no influence on visibility of objects unless the luminance contrast approaches zero.

Elstad JO, Fitzpatrick JT, Woltman HL. 1962. Requisite luminance characteristics for reflective signs. Highway Research Bulletin 336: 51-60.

- Optimal nighttime sign luminances were found in rural and suburban locations to be between 35 and $70 \mathrm{~cd} / \mathrm{m}^{2}$.

- In bright urban locations, nighttime sign luminances between 250 and $400 \mathrm{~cd} / \mathrm{m}^{2}$ were judged as prominently visible. 
Factors Affecting Sign Visibility, Conspicuity and Legibility

Bullough, J. D.

Interdisciplinary Journal of Signage and Wayfinding; Volume 1; Issue 2

Federal Highway Administration. 2004. Standard Highway Signs. Washington, DC: Federal Highway Administration.

- Guide signs on conventional roads in rural locations should have letters at least 6 in. high; in urban locations with low speed limits $(25 \mathrm{mph})$ letter height should be at least 4 in.

- Street name signs should have a letter height of 6 in.

- For signs other than on interstate highways, a legibility index of $40 \mathrm{ft} / \mathrm{in}$. should be used.

- Nearly all signs should have borders of the same color as the sign letters.

Fletcher K, Sutherland S, Nugent K. 2009. Identification of Text and Symbols on a Liquid Crystal Display, Part II: Contrast and Luminance Settings to Optimise Legibility. Edinburgh, Australia: Defence Science and Technology Organisation.

- For a positive contrast display, character luminance is recommended to be $20 \mathrm{~cd} / \mathrm{m}^{2}$ under dark lighting conditions, and $60 \mathrm{~cd} / \mathrm{m}^{2}$ under bright conditions.

- The background screen luminance is recommended to be $1 \mathrm{~cd} / \mathrm{m}^{2}$.

Forbes TW. 1972. Visibility and legibility of highway signs. In Human Factors in Traffic Safety Research. New York, NY: Wiley.

- A formula relating the conspicuity detection distance for a sign to its luminance, the contrast between the sign letters and their background, and the letter height is provided.

Forbes TW, Pain RF, Fry JP, Joyce RP. 1967. Effect of sign position and brightness on seeing simulated highway signs. Highway Research Record 164: 29-37.

- At night, higher sign luminance tended to be more likely to be detected.

- Under daytime conditions, darker signs were often most likely to be detected, but so were brighter signs, for many observers. The contrast between letters and the sign background might sometimes overcome the contrast between the sign and its own background.

Forbes TW, Snyder TE, Pain RF. 1965. Traffic sign requirements: I. Review of factors involved, previous studies and needed research. Highway Research Record 70: 48-56.

- Research is cited finding about $85 \%$ legibility to signs with a legibility index (ft of legibility distance per in of letter height) of $50 \mathrm{ft} / \mathrm{in}$.

- Only 3-4 short, familiar words can be read in a single glance at a sign.

- Letter-height to stroke-width ratios of 4-6 appear to be optimal for legibility.

- Color combinations providing the highest luminance contrast tend to provide the highest legibility.

- Use of fluorescent colors appears to have some advantages for sign detection.

- Brightness changes and motion are salient cues for peripheral vision. 
Factors Affecting Sign Visibility, Conspicuity and Legibility

Bullough, J. D.

Interdisciplinary Journal of Signage and Wayfinding; Volume 1; Issue 2

Freyssinier JP, Narendran N, Bullough JD. 2006. Luminance requirements for lighted signage. Proceedings of the SPIE, Vol. 6337, 63371M.

- Illuminated sign luminances between 40 and $190 \mathrm{~cd} / \mathrm{m}^{2}$ are optimal when no nearby signs are present.

- Illuminated sign luminances between 65 and $230 \mathrm{~cd} / \mathrm{m}^{2}$ are optimal when nearby signs are present.

Freyssinier JP, Zhou Y, Ramamurthy V, Bierman A, Bullough JD, Narendran N. 2003. Evaluation of light-emitting diodes for signage applications. Proceedings of the SPIE, Vol. 5187, pp. 309-317.

- The contrast of luminance variations within a sign character should be no greater than $0.2-0.4$ to achieve $80 \%$ acceptability.

- The size or spatial frequency of the luminance variations are relatively unimportant to judgments of acceptability.

Funkhouser D, Chrysler S, Nelson A, Park ES. 2008. Traffic sign legibility for different sign background colors: Results of an open road study at freeway speeds. Proceedings of the Human Factors and Ergonomics Society $52^{\text {nd }}$ Annual Meeting, pp. 1855-1859.

- Green and purple highway signs performed equivalently in a driving test in terms of legibility distances during daytime and nighttime.

Garvey PM. 2006. On-Premise Signs: Determination of Parallel Sign Legibility and Letter Heights. Bristol, PA: United States Sign Council Foundation.

- Reading performance begins to decline as the viewing angle changes from perpendicular with the sign surface to between $20^{\circ}$ and $40^{\circ}$ from perpendicular.

Garvey PM. 2007. Urban wayfinding signs: Evaluating exceptions to FHWA's standard alphabet. Transportation Research Board Annual Meeting, 17 p.

- A study of the use of the Futura font in wayfinding signs in Miami Beach found that it resulted in equivalent legibility as standard highway sign fonts.

Garvey PM, Chirwa KN, Meeker DT, Pietrucha MT, Zineddin AZ, Ghebrial RS, Montalbano J. 2004. New font and arrow for National Park Service guide signs. Transportation Research Record 1862: 1-9.

- A new highway sign font resulted in smaller word "footprints" but increased legibility distances by $10 \%$. 
Factors Affecting Sign Visibility, Conspicuity and Legibility

Bullough, J. D.

Interdisciplinary Journal of Signage and Wayfinding; Volume 1; Issue 2

Garvey PM, Klena MJ, Eie W-Y, Meeker DT, Pietrucha MT. 2016. Legibility of the Clearview typeface and FHWA standard alphabets on negative- and positive-contrast signs.

Transportation Research Record 2555: 28-37.

- Signs using the Clearview font outperformed identical signs using standard highway alphabets in terms of legibility distance.

- Predictions of relative visual performance were correlated with legibility distances for individual fonts, but legibility distances were lower than predicted by the visual performance model when the font aspect ratio was narrow.

Garvey PM, Kuhn BT. 2011. Highway sign visibility. In Handbook of Transportation Engineering (Kutz, M, editor). New York, NY: McGraw-Hill.

- Internally-illuminated signs and neon signs resulted in 40\%-60\% improvements in nighttime legibility over externally-illuminated signs.

Garvey PM, Pietrucha MT, Cruzado I. 2009. The Effects of Internally Illuminated OnPremise Sign Brightness on Nighttime Sign Visibility and Traffic Safety. Bristol, PA: United States Sign Council Foundation.

- Recognition distances at night to signs tend to increase as sign luminance increases, but decrease at the very highest luminances.

- Daytime signs were $43 \%$ more legible than poor nighttime signs, but only $13 \%$ more legible than well designed nighttime signs.

Garvey PM, Pietrucha MT, Meeker D. 1997. Effects of font and capitalization on legibility of guide signs. Transportation Research Record 1605: 73-79.

- Nighttime legibility distances to highway signs increased by $16 \%$ when Clearview font was used in place of the standard highway font.

Garvey PM, Zineddin AZ, Pietrucha MT. 2001. Letter legibility for signs and other large format applications. Proceedings of the Human Factors and Ergonomics Society $45^{\text {th }}$ Annual Meeting, pp. 1443-1447.

- A study of visual acuity using various fonts found Bank Gothic Light, Dutch Regular and Dutch Bold to be most legible, with Commercial Script Regular least legible.

- Letter width serves as a better predictor of legibility than stroke width.

Gates TJ, Carlson PJ, Hawkins HG. 2004. Field evaluations of warning and regulatory signs with enhanced conspicuity properties. Transportation Research Record 1862: 64-76.

- Use of fluorescent colors in highways signs increased desired driving maneuvers.

- A red border around speed limit signs reduced daytime driving speeds and reduced the number of speed violators during daytime and nighttime.

Goodspeed C, Rea MS. 1999. The significance of surround conditions for roadway signs. Journal of the Illuminating Engineering Society 28(1): 164.

- The speed with which observers could identify Landolt ring target orientation was correlated with the predicted relative visual performance model quantity. 
Factors Affecting Sign Visibility, Conspicuity and Legibility

Bullough, J. D.

Interdisciplinary Journal of Signage and Wayfinding; Volume 1; Issue 2

Graham JR, Fazal A, King LE. 1997. Minimum luminance of highway signs required by older drivers. Transportation Research Record 1573: 91-98.

- Young drivers require sign luminances of $30 \mathrm{~cd} / \mathrm{m}^{2}$ for correct identification from $90 \mathrm{~m}$, and $2 \mathrm{~cd} / \mathrm{m}^{2}$ from $60 \mathrm{~m}$.

- Older drivers require sign luminances in excess of $40 \mathrm{~cd} / \mathrm{m}^{2}$ for correct identification from $90 \mathrm{~m}$, and $7 \mathrm{~cd} / \mathrm{m}^{2}$ from $60 \mathrm{~m}$.

Hawkins HG, Picha DL, Wooldridge MD, Greene FK, Brinkmeyer G. 1999. Performance comparison of three freeway guide sign alphabets. Transportation Research Record 1692: 916.

- A comparison of different highway sign fonts showed increased legibility with Clearview over the standard highway font; the advantage was between $2 \%$ and $8 \%$.

Hawkins HG, Rose ER. 2005. A human factors study of the effects of adding dual logo panels to specific service signs. Transportation Research Board Annual Meeting, 18 p.

- Using two logos in the space normally allocated to a single logo on service signs resulted in lower recognition, but not so much that using dual logos should be prohibited in the authors' opinion.

Holick AJ, Carlson PJ. 2002. Model of overhead-sign luminance needed for legibility. Transportation Research Record 1801: 80-86.

- An equation for the sign luminance needed to achieve legibility as a function of driver age, visual acuity, stroke width and viewing distance is provided.

Institution of Lighting Engineers. 2001. Brightness of Illuminated Advertisements. Warwickshire, UK: Institution of Lighting Engineers.

- Large illuminated sign luminance at night should be limited to $300 \mathrm{~cd} / \mathrm{m}^{2}$ in low district brightness areas and $600 \mathrm{~cd} / \mathrm{m}^{2}$ in medium and high district brightness areas; large illuminated signs should not be used in intrinsically dark areas.

- Small illuminated sign luminance at night should be limited to $100 \mathrm{~cd} / \mathrm{m}^{2}$ in intrinsically dark areas, $600 \mathrm{~cd} / \mathrm{m}^{2}$ in low district brightness areas, $800 \mathrm{~cd} / \mathrm{m}^{2}$ in medium district brightness areas and $1000 \mathrm{~cd} / \mathrm{m}^{2}$ in high district brightness areas.

International Sign Association. 2007. Conspicuity and readability. Signline 51: 1-8.

- At a speed of $55 \mathrm{mph}$, a sign should be legible from a distance of $440 \mathrm{ft}$; at a speed of 30 $\mathrm{mph}$, it should be legible from $240 \mathrm{ft}$.

- On-premise signs should use letter heights of $7 \mathrm{in}$. for traffic at $25 \mathrm{mph}$, and $15 \mathrm{in}$. for traffic at $55 \mathrm{mph}$. 
Factors Affecting Sign Visibility, Conspicuity and Legibility

Bullough, J. D.

Interdisciplinary Journal of Signage and Wayfinding; Volume 1; Issue 2

Kinney GC, Showman DJ. 1967. Studies in Display Symbol Legibility: Part XVIII. The Relative Legibility of Uppercase and Lowercase Typewritten Words. Bedford, MA: The Mitre Corporation.

- Word forms produced by combinations of uppercase and lowercase letters were equivalent in legibility to those by all-uppercase letters.

- Uppercase letters are recommended for displays and applications other than "normal reading" of text.

Kuhn BT, Garvey PM, Pietrucha MT. 1997. Model guidelines for visibility of on-premise advertising signs. Transportation Research Record 1605: 80-87.

- The contrast between a sign and its immediate background is the primary determinant of one's ability to detect the sign in visually simple environments, perhaps more than size.

- Increased sign luminance results in increased conspicuity and can help overcome visual complexity of the sign's background in most cases.

- Sign color can increase the sign's conspicuity.

- Contrast between sign letters and the sign background is important for legibility with a luminance ratio of 12:1 being close to optimal.

- Increasing sign luminance generally improves nighttime legibility up to an optimal value of $75 \mathrm{~cd} / \mathrm{m}^{2}$. Sign luminance at night should not be below $2.4 \mathrm{~cd} / \mathrm{m}^{2}$.

- Legibility distances for graphical symbols were nearly always longer than for alphanumeric characters.

- Mixed-case characters result in greater legibility distances than uppercase-only.

- The optimal stroke-width to height ratio for positive contrast is 1:5, and 1:7 for negative contrast text.

- Positive contrast results in greater legibility than negative contrast.

- To read a sign, process the information, and execute a driving maneuver in response to it requires 5.5 seconds with signs containing five or fewer critical elements.

Kuhn BT, Garvey PM, Pietrucha MT. 1998. Sign Legibility: The Impact of Color and Illumination on Typical On-Premise Sign Font Legibility. Bristol, PA: United States Sign Council Foundation.

- Internal illumination and neon signs outperformed externally-lighted signs in terms of sign legibility.

- Positive contrast signs outperformed negative contrast signs in terms of legibility.

- No legibility differences between serif and non-serif fonts were identified.

Lerner ND, Collins BL. 1983. Symbol sign understandability when visibility is poor. Proceedings of the Human Factors Society $27^{\text {th }}$ Annual Meeting, pp. 944-946.

- The polarity of symbols and backgrounds made little difference on the recognition of symbolic signs.

- Filled symbols outperformed outline symbols in terms of recognition. 
Factors Affecting Sign Visibility, Conspicuity and Legibility

Bullough, J. D.

Interdisciplinary Journal of Signage and Wayfinding; Volume 1; Issue 2

\section{Lewin I. 2008. Digital Billboard Recommendations and Comparisons to Conventional} Billboards. Scottsdale, AZ: Lighting Sciences, Inc.

- It is recommended that the illuminance from a digital billboard at a distance between 150 $\mathrm{ft}$ (for small billboards) and $350 \mathrm{ft}$ (for very large billboards) not exceed $3 \mathrm{~lx}$.

Milburn NJ, Mertens HW. 1997. Evaluation of a Range of Target Blink Amplitudes for Attention-Getting Value in a Simulated Air Traffic Control Display, DOT/FAA/AM-97/10. Washington, DC: Federal Aviation Administration.

- Flashing or blinking text is more difficult to read than steady text.

Millar K. 2011. Designing for legibility. SignCraft (January/February): 42-44.

- A rule of thumb for letter height at various viewing distances is given: 4 in. per $100 \mathrm{ft}$ of viewing distance.

- At $30 \mathrm{mph}, 8$ in. letters are needed to ensure 5 seconds of readability; 4 in. letters ensure 3 seconds of legibility.

- At $60 \mathrm{mph}, 16$ in. letters are needed to ensure 5 seconds of readability; 8 in. letters ensure 3 seconds of legibility.

Pankok C, Kaber D, Rasdorf W, Hummer J. 2015. Driver attention and performance effects of guide and logo signs under freeway driving. Transportation Research Board Annual Meeting, $11 \mathrm{p}$.

- A comparison of guide signs and logo signs on the highway showed that guide signs received fewer and shorter visual fixations.

- Guide signs had more consistent eye-scan patterns than logo signs, probably because of the left-to-right nature of reading text on guide signs.

Powers LD. 1965. Effectiveness of sign background reflectorization. Highway Research Record 70: 74-86.

- Study participants were instructed to drive along a highway at night and exit following the presence of test signs equipped with no, low or highly-reflective green background sheeting material (resulting in different background luminances), with white reflectorized letters.

- No differences among the background conditions were found in terms of accuracy in responding to the test signs. 
Factors Affecting Sign Visibility, Conspicuity and Legibility

Bullough, J. D.

Interdisciplinary Journal of Signage and Wayfinding; Volume 1; Issue 2

Rea MS (editor). 2000. IESNA Lighting Handbook: Reference and Application, $9^{\text {th }}$ ed. New York, NY: Illuminating Engineering Society.

- Equations are provided for the spacing of individual lamps in exposed-letter signs, and for lamp wattages in different ambient environments.

- Sign luminance recommendations include $70-350 \mathrm{~cd} / \mathrm{m}^{2}$ for lighted fascia signs, 250-500 $\mathrm{cd} / \mathrm{m}^{2}$ for bright fascia signs, $450-700 \mathrm{~cd} / \mathrm{m}^{2}$ for low brightness areas, $700-1000 \mathrm{~cd} / \mathrm{m}^{2}$ for average commercial areas, 1000-1400 for areas with high sign competition, and 1400$1700 \mathrm{~cd} / \mathrm{m}^{2}$ for emergency traffic control.

- Floodlighted signs in bright surrounds should be illuminated to $1000 \mathrm{~lx}$ if reflectance is low, and $500 \mathrm{~lx}$ if reflectance is high; in dark surrounds, half these illuminances are recommended.

Rea MS, Ouellette MJ. 1991. Relative visual performance: A basis for application. Lighting Research and Technology 23(3): 135-144.

- The speed and accuracy of visual processing such as identifying characters in printed text is systematically related to its contrast, size, and the luminance of the background.

Schieber F, Goodspeed CH. 1997. Nighttime conspicuity of highway signs as a function of sign brightness, background complexity and age of observer. Proceedings of the Human Factors and Ergonomics Society $41^{\text {st }}$ Annual Meeting, pp. 1362-1366.

- Increasing sign luminance had no benefit in terms of response times or response accuracy to signs when backgrounds were simple, but did improve detection times and accuracy in visually complex environments.

Schnell T, Atkan F, Li C. 2004. Traffic sign luminance requirements of nighttime drivers for symbolic signs. Transportation Research Record 1862: 24-35.

- Sign luminance, letter contrast and the type of symbol displayed all influenced the legibility distance of sign symbols.

Schnell T, Yekhshatyan L, Daiker R. 2009. Effect of luminance and text size on information acquisition time from traffic signs. Transportation Research Record 2122: 52-62.

- The relative visual performance model resulted in close agreement with visual acquisition times in a study of sign character legibility under different luminances, sizes and contrasts.

Shurtleff D, Botha B, Young M. 1966. Studies in Display Symbol Legibility: Part IV. The Effects of Brightness, Letter Spacing, Symbol Background Relation and Surround Brightness on the Legibility of Capital Letters. Bedford, MA: The Mitre Corporation.

- Letters with high contrast against their backgrounds are recommended for highest acuity.

- Polarity of contrast is unimportant to legibility.

- Background luminances of 70 to $140 \mathrm{~cd} / \mathrm{m}^{2}$ are recommended. 
Factors Affecting Sign Visibility, Conspicuity and Legibility

Bullough, J. D.

Interdisciplinary Journal of Signage and Wayfinding; Volume 1; Issue 2

Smiley A, Persaud B, Bahar G, Mollett C, Lyon C, Smahel T, Kelman WL. 2005. Traffic safety evaluation of video advertising signs. Transportation Research Record 1937: 105-112.

- Video advertising is stated to have potential to distract drivers inappropriately, but overall impacts on safety are likely to be small.

Tinker MA. 1966. Experimental studies on the legibility of print: An annotated bibliography. Reading Research Quarterly 1(4): 67-118.

- Research is cited stating that letters with serifs are more legible than those without serifs.

- A study found that white numbers printed on a black background were $8 \%$ more legible than black numbers printed on a white background.

- The poorest color combinations for reading text were found in one study to be red type on black background, or vice versa. Luminance contrast is one of the most important factors in legibility.

- The optimal character stroke width was identified in research as being $18 \%$ of the character height or width.

- Research stating that increasing illumination could overcome a type size change from 12 to 6 points is cited.

Town of Bermuda Run. 2013. Sign Design Guidelines. Bermuda Run, NC: Town of Bermuda Run.

- A viewer reaction time of 8 seconds is recommended for signs along roads with a speak limit of $45 \mathrm{mph}$, when six or fewer words are on the sign.

- The ideal letter height for signs is stated to be between 8 and 13 in.

- For improved legibility, block (non-script) text and mixed case is preferred.

- Using no more than two colors is stated to increase legibility.

- Positive contrast signs are stated to increase legibility, but the degree of improvement depends upon illumination and contrast.

Town of Huntersville. 2009. Suggestions for Designing Effective Signs. Huntersville, NC: Town of Huntersville.

- High contrast between sign letters and their backgrounds is desirable for legibility.

- Light letters on dark backgrounds are preferable to the opposite for ease of reading.

- For 2-lane roads, $30 \mathrm{mph}$ traffic requires 8 -in. letters and $55 \mathrm{mph}$ traffic requires 12 -in. letters.

- For 4-lane roads, $30 \mathrm{mph}$ traffic requires 10-in. letters and $55 \mathrm{mph}$ traffic requires 15 -in. letters.

- Sign letters should occupy no more than $40 \%$ of the sign area. 
Factors Affecting Sign Visibility, Conspicuity and Legibility

Bullough, J. D.

Interdisciplinary Journal of Signage and Wayfinding; Volume 1; Issue 2

Ullman BR, Ullman GL, Dudek CL, Ramirez EA. 2005. Legibility distances of smaller letter light-emitting diode changeable message signs. Transportation Research Board Annual

Meeting, 23 p.

- LED letters on a changeable message sign with a height of 9 in. were legible from $228 \mathrm{ft}$ in the daytime and $114 \mathrm{ft}$ at night.

- LED letters on a changeable message sign with a height of 10.6 in. were legible from 324 $\mathrm{ft}$ in the daytime and $203 \mathrm{ft}$ at night.

U.S. Small Business Administration. 2003. The Signage Sourcebook. Washington, DC: U.S. Small Business Administration.

- It is recommended that a sign be legible from a distance (in $\mathrm{ft}$ ) equal to a vehicle's speed limit (in mph) multiplied by 8 .

- Signs mounted on the left side of the road require letters to be one-third larger than those on the right side of the road, for equal legibility.

- Recommended sign heights range from $12 \mathrm{ft}$ for $25-\mathrm{mph}$ traffic to $50 \mathrm{ft}$ for $55-\mathrm{mph}$ traffic.

Van Houten R, Healey K, Malenfant JEL, Retting R. 1998. Use of signs and symbols to increase the efficacy of pedestrian-activated flashing beacons at crosswalks. Transportation Research Record 1636: 92-95.

- Adding a pedestrian symbol sign near a flashing warning beacon increased the number of drivers who yielded to pedestrians.

Yager D, Aquilante K, Plass R. 1998. High and low luminance letters, acuity reserve, and font effects on reading speed. Vision Research 38: 2527-2531.

- At a high background luminance $\left(150 \mathrm{~cd} / \mathrm{m}^{2}\right)$ there is no difference in reading rates between serif and non-serif fonts.

- At a low background luminance $\left(0.15 \mathrm{~cd} / \mathrm{m}^{2}\right)$ a non-serif font resulted in improved reading rates over a serif font.

Young SL, Laughery KR, Bell M. 1992. Effects of two type density characteristics on the legibility of print. Proceedings of the Human Factors Society $36^{\text {th }}$ Annual Meeting, pp. 504508.

- Type width is stated to affect legibility more than inter-character spacing.

- Reducing the space between characters improved legibility for standard type widths, but decreased legibility for the narrowest fonts.

Zwahlen HT, Schnell T. 1998. Legibility of traffic sign text and symbols. Transportation Research Record 1692: 142-151.

- Sign legibility distances are 1.8 times longer in the daytime than they are at night. 